\title{
Tantangan Akuntan Di Era Revolusi Industri 4.0 Pada Masa Bonus Demografi Indonesia
}

\author{
Teresa Paulina Sihombing \\ Akuntansi, Fakultas Pascasarjana, Universitas Negeri Medan (UNIMED) \\ Medan, Indonesia \\ edithsiltor@gmail.com
}

\begin{abstract}
Indonesia gets the peak demographic bonus in 2020-2030, which is characterized by a higher number of productive ages compared to the number of non-productive ages. Along with this bonus demography, Indonesia also entered the era of industrial revolution 40. Of course this has become a challenge for all sectors, both the government, educational institutions and students who are prepared to enter the workforce with a new system, namely industry 4.0 where more work is taken by robotic system or technology. The accounting profession is one of the fields that is challenged to change in order to be able to face the challenges of the effects of the industrial revolution 4.0. This research is a descriptive literature study, where the researcher tries to discuss the challenges that will be faced by accountants and prospective accountants in the Indonesian demographic bonus period and in the era of industrial revolution 4.0.
\end{abstract}

Keywords: Accountant's challenge, industrial revolution 4.0

Abstrak-Indonesia mendapatkan puncak bonus demografi pada tahun 2020-2030, yang ditandai dengan jumlah usia produktif penduduk lebih tinggi dibandingkan dengan jumlah usia non produktif. Bersamaan dengan bonus demografi ini, Indonesia juga memasuki era revolusi industry 40. Tentu hal ini menjadi tantantangan untuk semua sector, baik itu pemerintah, lembaga pendidikan dan juga mahasiswa yang dipersiapkan memasuki dunia kerja dengan system baru yaitu industry 4.0 dimana semakin banyaknya pekerjaan diambil alih oleh system robot atau tehnologi. Profesi akuntan merupakan salah satu bidang yang ditantang untuk berubah agar mampu menghadapi tantangan dari efek revolusi industry 4.0. Penelitian ini merupakan studi pustaka deskriptif, dimana peneliti mencoba membahas tentang tantangan yang akan dihadapi akuntan dan calon akuntan di masa bonus demografi Indonesia dan dalam era revolusi industry 4.0.

Keywords: Tantangan akuntan, Revolusi industry 4.0

\section{PENDAHULUAN}

Istilah Bonus demografi dan revolusi industri 4.0 adalah istilah yang sudah sering kita dengarkan akhir-akhir ini. Kedua hal ini menjadi sesuatu yang sangat penting bagi Indonesia, sehingga pemerintah Indonesia menghidupkan kembali mata pelajaran teknologi informasi dan Komunikasi (TIK) dengan istilah baru yaitu Informatika pada tahun ajaran 2019/2020 yang diatur dalam Permendikbud 36 Tahun 2018[1]. Perubahan ini disebutkan dalam permendikbud tersebut untuk menjawab tantangan internal berkaitan dengan bonus demografi Indonesia dimana usia produktif (15-64) penduduk Indonesia lebih tinggi dari pada usia non produktif yaitu usia anak-anak ( 0-14) dan usia tua (diatas 64 tahun) lebih sedikit, dan penduduk usia produktif ini mencapai puncaknya pada tahun 2020-2030. Bonus demografi merupakan masa yang dimana suatu Negara mengalami bahwa 
usia produktif penduduknya lebih tinggi dari usia tidak produktif. Pada periode tersebut, penduduk usia produktif Indonesia diprediksi mencapai 64 persen dari total jumlah penduduk yang diproyeksikan sebesar 297 juta jiwa (Bapenas, 2017)[2]. Bonus demografi ini harus diimbangi dengan peningkatan kualitas dari sisi pendidikan dan keterampilan, termasuk kaitannya dalam menghadapi keterbukaan pasar tenaga kerja. Bersamaan dengan masa bonus demografi, Indonesia juga menghadapi era revolusi industry 4.0. Rohida (2018)[3] menjelaskan bahwa perubahan dunia kini tengah memasuki era revolusi industri 4.0 atau revolusi industri dunia keempat dimana teknologi informasi telah menjadi basis dalam kehidupan manusia. Segala hal menjadi tanpa batas (borderless) dengan penggunaan daya komputasi dan data yang tidak terbatas (unlimited), karena dipengaruhi oleh perkembangan internet dan teknologi digital yang masif sebagai tulang punggung pergerakan dan konektivitas manusia dan mesin. Revolusi industri 4.0 merupakan fase keempat dari perjalanan sejarah revolusi industri yang dimulai pada abad ke -18. Revolusi industri 1.0 ditandai dengan penemuan mesin uap untuk mendukung mesin produksi, kereta api dan kapal layar. Revolusi industri 2.0 ditandai dengan ditemukannya enerji listrik, yag mendorong para imuwan untuk menemukan berbagai teknologi lainnya seperti lampu, mesin telegraf, dan teknologi ban berjalan, dan revolusi Industri 3.0 yaitu revolusi industri lanjutan yang sering disebut revolusi teknologi dengan ditemukannya ponsel genggam, mesin kontrol, dan komputer. dan sekarang hendak memasuki revolusi industi 4.0 yang di awali dengan dari revolusi internet yang bukan hanya sebagai mesin pencari, namun lebih dari itu semua bisa terhubung dengan cerdas buatan yang dapat mengganti posisi manusia dalam mengerjakan suatu pekerjaan(Yahya, 2018)[4].

Tingginya jumlah usia produktif Indonesia di masa bonus demografi mengharuskan penduduk usia produktif harus memiliki keahlian untuk mampu bersaing untuk mendapatkan kesempatan dalam dunia usaha, tentu ini menjadi tantangan bagi para mahasiswa yang akan terjun ke dunia kerja, bagaimana mereka mempersiapkan mental dan keahlian untuk menghadapi masa bonus demografi Indonesia di era revolusi industry 4.0, dimana adanya beberapa pekerjaan telah dapat dikerjakan oleh system dan robotic. Bidang akuntansi merupakan salah satu bidang yang harus mempersiapkan diri pada era revolusi industry 4.0 ini, karena akuntansi akan mengalami perubahan mengikuti perubahan system kerja perusahaan dan organisasi. Efek Revolusi Industri 4.0 terhadap dunia akuntansi bisa terdapat pada (1) Perubahan Proses Bisnis, (2) Internet of think, (3) Cyber Security, dan (4) Artificial Intelegency (Sari, 2018) [5]. Maka revolusi industry 4.0 pada masa bonus demografi Indonesia ini menjadi tantangan besar bagi mahasiswa akuntansi yang mempersiapkan diri untuk memasuki dunia kerja saat ini. Tantangan ini harus dijawab para mahasiswa dengan membuka diri pada perkembangan zaman untuk membekali diri dengan berbagai keahlian agar dapat memasuki dunia kerja.

\section{METODOLOGI PENELITIAN}

Penelitian ini menggunakan metode analisis deskriptif kualitatif berbasis kajian pustaka, dimana peneliti mencoba membahas tentang tantangan yang akan 
dihadapi akuntan dan calon akuntan di masa bonus demografi Indonesia dan dalam era revolusi industry 4.0 berdasarkan pada pengumpulan data yang dilakukan peneliti. Studi kepustakaan merupakan instrumentasi penelitian dengan mengumpulkan berbagai macam literatur relevan, baik jurnal, buku, proceeding maupun working paper, yang memiliki tersangkut paut dengan permasalahan penelitian ini. Berikut adalah langkah-langkah yang ditempuh untuk menganalisis data. Pertama adalah melakukan studi pendahuluan dengan meneliti kajian-kajian terdahulu yang membahas masalah tantangan akuntan dan calon akuntan di era revolusi industry 4.0. Kedua adalah mengumpulkan literatur yang sesuai dengan fokus permasalahan yang menjadi tema utama penelitian ini. Ketiga adalah menganalisis secara kritis berbagai sumber literatur tersebut untuk mendapatkan pemahaman mendasar mengenai korelasi revolusi industry 4.0 dengan tantangan yang akan dihadapi akuntan. Keempat adalah menulis makalah berdasarkan argumentasi analisis dari berbagai data tersebut.

\section{HASIL DAN PEMBAHASAN}

\subsection{Revolusi Industry 4.0 dan Dunia Kerja}

Revolusi industri 4.0 menjadi tantangan bagi generasi milineal. Widiarini (2018)[6] mengutip pernyataan Direktur Jenderal (Dirjen) Pembinaan, Pelatihan, dan Produktivitas Kemenaker Bambang SL, bahwa akan ada jenis pekerjaan yang hilang seiring berkembangnya revolusi industri 4.0, sebanyak 57 persen pekerjaan yang ada saat ini akan tergerus oleh robot. Sementara Indonesia pada saat yang sama mengalami bonus demografi dimana jumlah penduduk usia produktif lebih tinggi dibandingkan jumlah usia non produktif. Bonus demografi yang sedang dialami Indonesia ini merupakan buah dari keberhasilan dalam mengendalikan laju pertumbuhan penduduk selama empat dekade terakhir. Bonus demografi ini dihasilkan dari adanya keluarga berencana tahun 1970-2000an yang berjumlah lebih dari 80.000.000 jiwa (D. UI, 2015)[7]. Ini juga menjadi tantangan bagi penduduk usia produktif dalam bersaing mendapatkan peluang kerja di masa bonus demografi Indonesia. Gerd Leonhard dalam Vitriano (2018)[8] memprediksikan bahwa secara global, era industry digital akan menghilangkan 11.5 juta pekerjaan dari rentang tahun 2015 sampai dengan 2025 dikarenakan alasan faktor manusia akan digantikan oleh mesin. Dan Cutler dan lewis mengemukakan dalam Iswanto \& Wahjono (2019)[9] bahwa di negara Inggris saja, teknologi berkontribusi menghilangkan 800.000 pekerjaan. Shanto dalam SPN News (2018)[10] mengutip pernyataan Direktur Jenderal (Dirjen) Pembinaan, Pelatihan, dan Produktivitas Kemenaker Bambang SL yang mengatakan bahwa di balik hilangnya beberapa pekerjaan akan muncul juga beberapa pekerjaan baru. Bahkan, jumlahnya diprediksi sebanyak 65.000 pekerjaan. Maka, yang harus dilakukan sekarang adalah menyesuaikan diri dengan perubahan tersebut.

Revolusi industry 4.0 mengubah system kerja dan bahkan sebagian banyak pekerjaan akan diambil alih system robotic, sementara penduduk usia produktif Indonesia tinggi sehingga membutuhkan usaha-usaha untuk meningkatkan roda perekonomian yang dapat menyerap tenaga kerja. Dengan demikian sumber daya manusia yang akan terjun ke dunia kerja harus memiliki keahlian khusus dan pribadi yang mau berkembang mengikuti perubahan system kerja. Hal ini 
diperlukan bukan hanya karena banyaknya jumlah penduduk usia produktif yang bersaing, tapi juga karena perubahan system kerja efek dari era revolusi industry 4.0, sehingga pada saat ini mahasiswa harus mempersiapkan dirinya untuk mengikuti perubahan system tersebut. Lembaga-lembaga pendidikan sebagai lembaga yang mempersiapkan tunas-tunas muda bangsa yang akan terjun ke dunia kerja juga harus terlibat. Pemerintah dalam hal ini, ikut serta andil dalam mempersiapkan SDM tersebut dengan memasukkan kembali mata pelajaran informatika dalam pembelajaran sekolah sejak usia dini, dengan membentuk tim untuk menyusun system pembalajaran yang tepat berkaitan dengan mata pelajaran tersebut sesuai dengan tingkat sekolah. Usaha-usaha ini dilakukan untuk menjawab tantangan dari era revolusi industry 4.0.

\subsection{Tantangan Akuntan di Era Revolusi Industri 4.0}

Menghadapi era industri termutakhir masa kini, perkembangan ekonomi digital telah membuka berbagai kemungkinan baru sekaligus meningkatkan resiko secara bersamaan. Perubahan tersebut memberikan dampak signifikan dalam perkembangan akuntansi. Di era digital dan perkembangan teknologi seperti sekarang, arus informasi berjalan begitu cepat, teknologi internet telah mengubah pandangan seseorang dalam mendapatkan informasi, termasuk dalam dunia akuntansi bisnis. Perkembangan teknologi mengubah bisnis, menjadikan tidak banyaknya sumber daya manusia yang dibutuhkan dalam bisnis termasuk staf akuntansi. Hal ini mengakibatkan Profesi akuntan underestimate terkait dampak teknologi terhadap pekerjaan akuntan. Ini menjadikan tantangan berat yang harus dijawab.

Pada era revolusi industry 4.0 akuntan sudah mulai dihadapkan pada beberapa posisi seperti; (1)Signal admit to noise, yaitu posisi dimana Akuntan sudah menyadari adanya ancaman akan profesinya, dan keasadaran ini membuat akuntan harus mempersiakan diri untuk menangkap peluang dari ancaman tersebut untuk dapat diambil sisi manfaatnya, (2)Changes takes hold, yaitu Akuntan sudah mulai merasa adanya perubahan dalam aktifitasnya namun merasa tidak perlu mengambil sikap dikarenakan belum menganggu "status quo", (3) The inevitable transformation, yaitu Akuntan sudah melakukan perubahan dikarenakan kinerja " status quo " sudah terganggu dengan adanya revolusi ini dan akuntan harus melakukan transformasi perubahan dengan cepat dan metode terbaik hanya untuk beberapa aspek yang dipandang perlu, dan (4) Adapting to the new normal yaitu adanya transformasi profesi akuntan secara menyeluruh sesuai tuntutan model baru industry 4.0, atau profesi akuntan akan hilang apabila tidak mampu beradaptasi terhadap perubahan tersebut (Iswanto \& Wahjono ,2019).

Perlunya transformasi profesi akuntan sesuai dengan tuntutan model baru industry 4.0 akan berefek terhadap dunia akuntansi, hal ini bisa terdapat pada:

a. Perubahan Proses Bisnis. Perkembangan teknologi akan mengubah system kerja bisnis, hal ini berkaitan dengan; (1) bagaimana pendanaan atas bisnis seperti perubahan asset perusahaan yang akan banyak berupa "teknologi", (2) Sumber daya yang dibutuhkan dalam bisnis tidak banyak lagi membutuhkan SDM karena pekerjaan akan banyak dikerjakan teknologi, bisa termasuk staf 
akuntansi, (3)pembuatan dan pengembangan perusahaan baru akan lebih pada berbasis virtual office / shop, dan (4) cara menjual produk dan jasa sudah melalui online marketplace.

b. Internet of thing. Internet of Thing (IoT) adalah sebuah konsep dimana suatu objek yang memiliki kemampuan untuk mentransfer data melalui jaringan tanpa memerlukan interaksi manusia ke manusia atau manusia ke komputer. IoT telah berkembang dari konvergensi teknologi nirkabel, microelectromechanical systems (MEMS), dan Internet (idcloudhost, 2016)[11].

c. Cyber Security. Keamanan Siber dapat digambarkan di satu sisi sebagai kebijakan, pedoman, proses, dan tindakan yang diperlukan agar transaksi elektronik dapat dilakukan dengan risiko pelanggaran, intrusi, atau pencurian minimum. Dan di sisi lain, keamanan siber adalah alat, teknik, atau proses yang digunakan untuk melindungi aset sistem informasi. Keamanan siber terdiri dari infrastruktur "lunak" dan "keras". Komponen infrastruktur lunak adalah Sumber Daya Manusia pengelola maupun pembuat kebijakan (people); dan kebijakan, proses, protokol, dan pedoman yang menciptakan lingkungan pelindung untuk menjaga sistem dan data (process). Sedangkan infrastruktur keras adalah technology yang terdiri dari perangkat keras dan perangkat lunak, yang dibutuhkan untuk melindungi sistem dan data dari ancaman eksternal dan internal siber (Islami, 2017)[12].

d. Artificial Intelegency (AI). AI merupakan rangkaian program kecerdasan yang digabungkan agar dapat memiliki rasa dan pemikiran seperti layaknya manusia tetapi dengan kapasitas lebih jauh. Bahkan dapat melakukan analisis untuk pola dan tren dengan jangka waktu yang lebih panjang.Hasilnya adalah berupa informasi yang disajikan secara lebih cepat, akurat dan terstruktur. Informasi ini kemudian dieksekusi oleh para eksekutif di dunia bisnis untuk meningkatkan usahanya (Natawijaya, 2018)[13].

Potensi teknologi menggantikan peran profesi akuntan hanya menunggu waktu. Peran akuntan akan bersifat strategis dan konsultatif. Maka dari itu akuntan perlu memiliki sertifikasi misalnya fasih berteknologi, supaya mampu bertahan dalam bersaing. Seorang akuntan juga harus memiliki strategi, diantaranya penguasaan soft skill baik interpersonal skills maupun intra-personal skills, Business understanding skills dan technical skills agar mampu menjawab tantangan diera digital ini. Senada dengan hal tersebut Zubaidah (2019)[14] mengutip informasi dari kepala pusat pembinaan profesi Keuangan pekertariat Jendral Kementrian Keuangan RI yang menginformasikan bahwa besarnya kemungkinan profesi akuntan tergantikan oleh robot adalah 95 persen. Besaran prosentase tersebut dikarenakan perkembangan Robotics and Data Analytics (Big Data) yang mengambil alih pekerjaan dasar yaNg dilakukan oleh akuntan (mencatat transaksi, mengolah transaksi, memilah transaksi). Oleh sebab itu, disarankan agar para akuntan dan calon akuntan untuk mulai mempelajari programming dan algoritma serta harus mengembangkan kompetensi yang penting bagi seorang akuntansi yaitu data analysis, information technology development and leadership skills.

Seorang akuntan harus aware terhadap perkembangan revolusi industri 4.0 dengan melihat kesempatan yang ada. Perusahaan-perusahaan dapat kehilangan 
daya saingnya apabila tidak menghiraukan perubahan-perubahan ini ke dalam strategi bisnis dan strategi kepemimpinan mereka. Hal ini juga merupakan tekanan untuk institusi pendidikan agar membuat kurikulum yang relevan bagi mahasiswa akuntansi untuk menyesuaikan dengan konektivitas digital sehingga diharapkan para lulusan yang akan menjadi akuntan mampu beradaptasi di era digital saat ini. Perubahan era memang tidak bisa dihindari, maka dari itu harus selalu bisa mengontrol reaksi dan sikap terhadap perubahan tersebut agar bisa ikut maju mengikuti perkembangan zaman. Dalam sektor akuntansi, berbagai tantangan yang hadir seiring datangnya era digital tak bisa dibiarkan begitu saja, harus dipelajari dengan baik agar dapat menentukan sikap untuk mengatasinya. Fasih berteknologi merupakan salah satu kunci menghadapi tantangan di era revolusi industry 4.0 saat ini bagi mahasiswa akuntansi, sehingga bonus demografi dapat menyerap tenaga kerja di bidang akuntansi.

\section{KESIMPULAN}

Revolusi Industri 4.0 pada masa bonus demografi menjadi tantangan bagi seluruh aspek dalam mempersipkan tenaga kerja dimasa mendatang. Pergeseran tenaga kerja manusia ke arah digitalisasi sebagai karakteristik industry 4.0 merupakan bentuk tantangan yang perlu direspon oleh para mahasiswa, lembaga pendidikan, dan pemerintah. Secara khusus dalam hal ini mahasiswa akuntansi sebagai calon akuntan, dimana profesi akuntan 95\% diprediksi akan ikut mengalami perubahan system kerja efek dari industry 4.0. Tantangan yang akan dihadapi akuntan ke depan berkaitan dengan fungsi profesinya terdapat pada perubahan proses bisnis, Internet of Thing (IoT), cyber security, dan artificial Intelegency (AI). Maka tantangan ini harus dijawab oleh akuntan dan calon akuntan dengan memiliki keahlian fasih berteknologi supaya mampu bertahan dalam bersaing, memiliki strategi seperti penguasaan soft skill baik interpersonal skills maupun intra-personal skills, Business understanding skills dan technical skills.

\section{DAFTAR PUSTAKA}

[1] “Permendikbud 36 Tahun 2018," 2018.

[2] Bapenas, "Siaran Pers Bonus Demografi 2020-2030: Strategi Indonesia Terkait Ketenagakerjaan dan Pendidikan," in kementerian PPN, 2017.

[3] L. Rohida, "Pengaruh Era Revolusi Industri 4.0 terhadap Kompetensi Sumber Daya Manusia," J. Manaj. dan Bisnis Indones., vol. 6, no. 1, pp. 114-136, 2019.

[4] M. Yahya, "Era Industri 4.0: Tantangan Dan Peluang Perkembangan Pendidikan Kejuruan Indonesia, Disampaikan dalam Pidato Pengukuhan Guru Besar Disampaikan pada Sidang Terbuka Luar Biasa Senat Universitas Negeri Makassar Tanggal 14 Maret 2018," J. Med. Vol 29, Nomor 1, Ed. April., vol. 29, no. 1, April, 2018.

[5] N. Z. M. Sari, "Dunia Akuntansi Menuju Revolusi Industri 4.0," no. December, 2018.

[6] A. D. Widiarini, 'Skill' yang Harus Dimiliki di Era Industri 4.0." https://edukasi.kompas.com/read/2018/10/31, 2018.

[7] D. K. dan A. S. B. F. UI, "Analisis Bonus Demografi Sebagai Kesempatan Memacu Perpercepatan Industri di Indonesia Oleh : Departemen Kajian dan Aksi Strategis BEM FEB UI 2015," 2015.

[8] O. Vitriano, "Industri 4.0 dan Kebutuhan Skill ASN," 2018.

[9] W. W.- Iswanto, "Pengaruh Revolusi Industri 4.0 Terhadap Ilmu Akuntansi-Esai," Amikjtc.Com, vol. 1, pp. 1-6, 2019. 
[10] Shanto, "Kemampuan Yang Harus Dimiliki di Era Revolusi Industri 4.0." https://spn.or.id, 2018.

[11] Idcloudhost, “Mari Mengenal Apa itu Internet of Thing (IoT).” https://idcloudhost.com, 2016.

[12] M. J. Islami, "Tantangan Dalam Implementasi Strategi Keamanan Siber Nasional Indonesia Ditinjau Dari Penilaian Global Cybersecurity Index," Masy. Telemat. Dan Inf. J. Penelit. Teknol. Inf. dan Komun., vol. 8, no. 2, p. 137, 2019.

[13] A. Natawijaya, "Hubungan 'Artificial Intelligence' dengan Pertumbuhan Bisnis." https://www.kompasiana.com, 2018.

[14] L. Zubaidah, "Finansial Akuntansi di Era Revolusi Industri 4.0." https://www.kompasiana.com, 2019. 